\title{
Análise do emprego turístico de Mato Grosso do Sul com o uso de medidas locacionais - 2006 a 2013
}

\author{
Analysis of the Mato Grosso do Sul tourist employment with the use of local \\ measures - 2006 to 2013 \\ El empleo del sector del turismo de Mato Grosso del Sur - 2006-2013
}

\author{
Luciana Virginia Mario Bernardo ${ }^{1}$ \\ Maycon Jorge Ulisses Saraiva Farinha²
}

Recebido em 10/03/2018; revisado e aprovado em 22/05/2018; aceito em 17/06/2018

DOI: http://dx.doi.org/10.20435/inter.v0i0.1879

\begin{abstract}
Resumo: o objetivo da pesquisa é analisar a especialização e a concentração do emprego turístico em Mato Grosso do Sul. Os procedimentos metodológicos foram o Quociente Locacional, Coeficiente de Redistribuição, Coeficiente de Localização e a Participação relativa desse emprego em relação ao emprego nacional. Os resultados indicam especialização do emprego turístico do estado, em municípios como Corumbá, contudo não há padrões de concentração. O coeficiente de redistribuição mostrou que não houve mudanças no padrão de localização no decorrer do período, e a participação relativa do emprego não é constante.

Palavras-chave: aglomerações; especialização do emprego turístico; análise regional; economia do trabalho.

Abstract: the objective of the research is to analyze the specialization and concentration of tourist employment in Mato Grosso do Sul. The methodological procedures were the Locational Quotient, Redistribution Coefficient, Location Coefficient and the Relative Participation of this employment in relation to the national employment. The results indicate specialization of the state's tourism employment, in municipalities like Corumbá, however, there are no concentration patterns. The redistribution coefficient showed that there were no changes in the pattern of location during the period, and the relative share of employment is not constant. Keywords: agglomerations; specialization of tourism employment; regional analysis; labor economics.

Resumen: el objetivo de la investigación es analizar la especialización y la concentración del empleo turístico en Mato Grosso do Sul. Los procedimientos metodológicos fueron el Cociente de Redistribución, Coeficiente de Ubicación y la Participación relativa de este empleo en relación al empleo nacional. Los resultados indican especialización del empleo turístico del estado, en municipios como Corumbá, sin embargo, no hay patrones de concentración. El coeficiente de redistribución mostró que no hubo cambios en el patrón de localización durante el período, y la participación relativa del empleo, no es constante.
\end{abstract}

Palabras clave: aglomeraciones; especialización del turismo de empleo; regional análisis; economía del trabajo.

\section{INTRODUÇÃO}

As perspectivas globais para o turismo demonstram que o setor está em expansão e poderá, até o ano de 2030, obter resultado quatro vezes maior que os já quantificados no setor dos voos domésticos da aviação de transporte de passageiros (WORLD TOURISM ORGANIZATION [UNWTO], 2011). As atividades turísticas tendem a contribuir com a geração de empregos locais e com a manutenção das características ambientais do espaço rural (DURHAM, 2008; STRONZA, 2008; HOEFLE, 2016). Ainda, auxiliam na redução do êxodo rural, por gerar atividades auxiliares no desenvolvimento socioeconômico e na preservação de elementos culturais das comunidades (SCÓTOLO; PANOSSO NETTO, 2015 ; FAGUNDES; ASHTON, 2016). Principalmente pequenos empreendimentos turísticos, tendem a adquirir produtos produzidos no local ou na região em que estão inseridos, o fato possibilita ampliar o efeito multiplicador da renda e auxiliar no desenvolvimento da região (ANTHOPOULOU; MELISSOURGOS, 2012).

\footnotetext{
${ }^{1}$ Universidade Estadual do Oeste do Paraná (Unioeste), Toledo, Paraná, Brasil.

${ }^{2}$ Universidade Federal da Grande Dourados (UFGD), Dourados, Mato Grosso do Sul, Brasil.
} 
No Brasil, as atividades turísticas se consolidam e impulsionam o desenvolvimento socioeconômico (ARAÚJO, 2014). A atividade econômica amplia suas proporções e procura melhorar sua qualidade para ser equivalente a padrões internacionais (EICHENBERG; SILVA, 2013). O estado de Mato Grosso do Sul é considerado um relevante destino turístico do país; entre as localidades que se destacam, estão as áreas de planície alagada que compõem o bioma Pantanal e a Serra da Bodoquena, exemplos de beleza cênica existente no estado (MARIANI; SORIO; ARRUDA, 2011). Observa-se que aproximadamente $40 \%$ dos atrativos turístico deste estado são naturais e ecológicos. Em 2012, o setor registrou o uso de serviços turísticos no estado por 1.603.722 turistas (SECRETARIA DE ESTADO DE MEIO AMBIENTE E DESENVOLVIMENTO ECONÔMICO [SEMADE], 2015).

Acredita-se que investimentos nas atividades turísticas possam contribuir com a diversificação da economia do Estado de Mato Grosso do Sul. Tendo em vista que o conjunto de atividades do comércio e de serviços contribuíram com a arrecadação de 78,4\% do Imposto de Circulação de Mercadorias e Serviços (ICMS). Essa tributação é uma receita estadual responsável pelo pagamento de diferentes serviços públicos executados pelo estado para atendimento das necessidades da população (SEMADE, 2015). Ou seja, serviços estaduais que podem contribuir com o desenvolvimento dos municípios, por melhorar a qualidade de vida dos indivíduos. Cabe indicar que, para a expansão das atividades turísticas, é necessário que existam pessoas interessadas em atuar no setor (empreendedores e trabalhadores) e outras disponíveis para deslocar-se até o local (consumidores) (SCÓTOLO; PANOSSO NETTO, 2015). Dessa forma, o objetivo da pesquisa é analisar a concentração do emprego turístico em Mato Grosso do Sul e sua relação com o desenvolvimento local. Denota-se que foi feito uso de medidas locacionais para a análise do emprego turístico do estado. A partir do uso dessas medidas é revelado o grau de importância do emprego turístico por município, no mercado de trabalho regional, ao qual esse emprego pode ser considerado um fator do desenvolvimento da região.

\section{MATERIAIS E MÉTODO}

Para realizar a análise da concentração do emprego turístico em Mato Grosso do Sul, foram adotadas, como procedimentos metodológicos, medidas de localização. Estudos como o de Crocco et al. (2006) sobre aglomerações produtivas locais; Bastos e Almeida (2008) para aglomerações industriais em Minas Gerais; Baptista, Pereira e Sonaglio (2016), em relação à dinâmica do setor turístico em Ponta Porã, Mato Grosso do Sul; Lacerda e Santos (2017) para a concentração do emprego agropecuário em Pernambuco; e Matei e Matei (2017), sobre a localização e especialização da Região Sul do Brasil, são adotados como bases para o desenvolvimento desta pesquisa.

A primeira medida de localização utilizada foi o Quociente Locacional (QL) (1), o qual é definido como a participação do emprego do setor i da região j, em relação à região de referência, sendo:

$$
\boldsymbol{Q L}=\frac{E_{i j}}{E_{i}} / \frac{E_{j}}{E}
$$

Ao qual,

$\mathrm{E}_{\mathrm{ij}}$ : emprego do setor turístico no município j;

$E_{\mathrm{i}}$ : emprego total do setor do turismo no estado de Mato Grosso do Sul; 
$E_{i}$ : emprego total do município j;

E: emprego total de Mato Grosso do Sul.

A interpretação do QL representa o grau de especializawwçãwo do município j no setor do turismo, quanto maior o QL maior a concentração. Desta forma, tem-se o Quadro 1.

Quadro 1 - Interpretação do QL referente ao emprego turístico em Mato Grosso do Sul

\begin{tabular}{|c|l|}
\hline Valor QL & \multicolumn{1}{|c|}{ Interpretação } \\
\hline $\mathbf{Q L}=\mathbf{0}$ & Região não possui especialização. \\
\hline $\mathbf{0}<\mathbf{Q} \geq \mathbf{1}$ & Região tem grau de especialização igual ao do estado. \\
\hline $\mathbf{Q L}>\mathbf{1}$ & $\begin{array}{l}\text { Há concentração da atividade econômica no município superior à concentração dessa } \\
\text { atividade no estado. }\end{array}$ \\
\hline
\end{tabular}

Fonte: Elaborado a partir de Vidigal, Campos e Rocha (2009).

A segunda medida utilizada foi o coeficiente de redistribuição, este identifica se está sendo estabelecido algum padrão de concentração no decorrer do período analisado. Para isso, o coeficiente relaciona a distribuição percentual de empregos do setor em dois períodos distintos (2) para as microrregiões de Mato Grosso do Sul.

$$
\boldsymbol{C R e d}=\sum_{j}\left[\left(\frac{E_{i j}^{t 1}}{\sum_{j} E_{i j}}\right)-\left(\frac{E_{i j}^{t 0}}{\sum_{j} E_{i j}}\right)\right] / 2
$$

Ao qual,

$\mathrm{E}_{\mathrm{ij}}^{\mathrm{tx}}$, representa o emprego no setor turístico no município j, nos anos 0 e 1;

$\sum_{j} E i j$, representa o emprego no setor turístico no estado de Mato Grosso do Sul;

$\mathrm{t} 0=2006$;

$\mathrm{t} 1=2013$.

A interpretação do CRed, segundo Lima et al. (2006),

- Os valores próximos a 0 indicam que não ocorreram mudanças significativas no padrão espacial de localização da modalidade;

- Os valores próximos a 1 indicam uma redistribuição significativa.

A terceira medida utilizada foi o coeficiente localização (CL) (3), a qual relacionou a distribuição percentual do emprego do setor turístico com a distribuição do emprego de todos os setores do estado.

$$
\boldsymbol{C L}=\sum_{j}\left|\left(\left(E_{i j} / \sum_{j} E_{i j}\right)-\left(\sum_{i} E_{i j} / E\right)\right) / 2\right|
$$

A interpretação dos resultados segundo Lima et al. (2006) e Mattei e Mattei (2017) é:

- CL próximo ou igual a 0 , o setor turístico é distribuído regionalmente da mesma forma que o conjunto de todos os setores da economia de Mato Grosso do Sul; 
- CL próximo ou igual a 1, o setor turístico apresenta uma concentração regional mais intensa que o conjunto de todos os setores.

A quarta medida de que se fez uso foi a participação relativa do emprego do setor turístico de Mato Grosso do Sul, no emprego total do mesmo setor no país (4).

$$
\boldsymbol{P} \boldsymbol{R}=\sum_{j} E_{i j} / E t
$$

$E t$, corresponde ao emprego total do setor turístico do Brasil. Observa-se que, quanto maior o resultado, maior a participação do emprego do setor turístico de Mato Grosso do Sul em relação ao emprego do setor no país. Os indicadores QL e PR foram calculados para os anos 2006, 2009 e 2013, pelos quais se optou devido à disponibilidade de informações. Os dados foram extraídos da Relação Anual de Informação Social (RAIS), disponibilizados pelo Ministério do Trabalho, conforme as especificações às medidas locacionais.

\section{RESULTADOS E DISCUSSÃO}

O QL foi calculado para os anos 2006, 2009 e 2013, para Mato Grosso do Sul (Figura 1). Nesse período, é perceptível que a maioria dos municípios não possui especialização em relação às atividades turísticas. Contudo a concentração, de forma geral, dessas atividades pode ser representada por 23\% em 2006, 24,4\% em 2009 e 28\% em 2013 dos municípios do estado. 0 número de municípios com concentração igual à do estado é maior que o número de municípios com concentração superior à do estado. Porém essa diferença é pequena, de 2,5\% em 2006 e 2013 e de 3,8\% em 2009. Além disso, é observado que a concentração da atividade maior que a do estado repete-se, nos três anos, em alguns municípios, quais sejam: (i) Corumbá, (ii) Aquidauana, (iii) Porto Murtinho, (iv) Ponta Porã e (v) Bonito.

Os municípios, (i) Aquidauana, (ii) Corumbá, (ii) Porto Murtinho são aqueles que auxiliam na formação da mesorregião dos pantanais sul-mato-grossenses. Além disso, os dois primeiros municípios compõem a região turística do Pantanal (GURGEL, 2016). Depreende-se que a região constituída pelo bioma Pantanal, em Mato Grosso do Sul, desde o final da década de 1970 é considerada um local de desejo dos turistas (GARMS, 2004). Tendo em vista que, historicamente, essa região possui um fluxo de atividades da pesca, este é atribuído à primeira fase do desenvolvimento do turismo de Mato Grosso do Sul, cuja oferta dos serviços foi relacionada aos municípios como Corumbá, Aquidauana entre outros (VIOLIN; ALVES, 2017). As atividades turísticas são consideradas alternativas na geração de emprego, uma vez que a atração de turistas para a região pode ser refletida em outros setores econômicos, auxiliando na geração de renda e no desenvolvimento local e regional (WEARING; NEIL, 2014).

Os municípios de Bonito e Ponta Porã não estão localizados em uma mesma mesorregião. Além disso, possuem atividades turísticas distintas. O primeiro município é referência no Brasil em relação ao ecoturismo, e a região em que está inserido passou a ser a mais visitada nos últimos anos (OLIVEIRA, 2011). Passou a desenvolver atividades turísticas desde o início da década de 1990, para isso, investiu em infraestruturas que atendessem as demandas dos turistas (LEONEL et al., 2017). Ele é caracterizado como área turística regional e nacional, devido ao número de atrativos oferecidos, vinculados à natureza (MARIANI, 2003). No município de Ponta Porã, observa-se 
o desenvolvimento de atividades turísticas distintas ao primeiro caso. Considerado um micropolo fronteiriço, o município integra-se a Pedro Juan Caballero-Paraguai, por meio da economia e da cultura. Essa integração é facilitada pela linha de fronteira seca que une o urbano brasileiro com o paraguaio, existente nos dois municípios (SANTOS; SILVA; MOREIRA JUNIOR, 2015).

Devido à fronteira seca com o Paraguai, a atividade turística com maior representatividade no município de Ponta Porã são as compras (BAPTISTA; PEREIRA; SONAGLIO, 2016). Estima-se a passagem de 200 mil pessoas por mês pelo município (PREFEITURA MUNICIPAL DE PONTA PORÃ, 2013). Em eventos específicos como a Black Friday, no ano de 2013, acredita-se que o fluxo de brasileiros, tenha sido de 120 mil turistas em três dias (PEREIRA et al., 2014). Por outro lado, há potencialidades históricas, ainda não utilizadas para atração de visitantes ao município, tendo em vista que, na região, iniciou-se e encerrou-se a Guerra do Paraguai, sendo esta considerada o maior conflito entre Nações da América Latina (DORATIOTO, 2002). 
$\stackrel{n}{\circ}$

(1)

ᄋ

อุ

$\stackrel{\sim}{\frac{1}{C}}$

जे

웅

品

过

$\stackrel{\circ}{\stackrel{0}{\pi}}$

$\sum_{\varepsilon}$

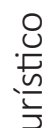

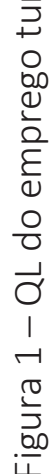
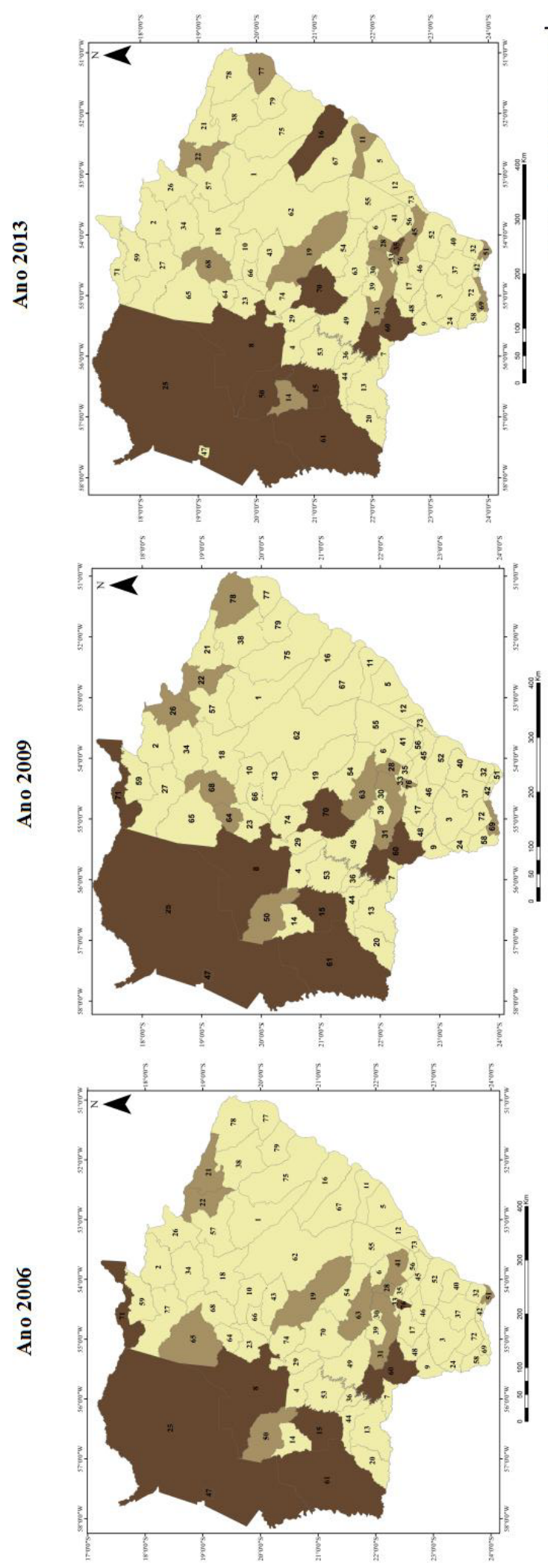

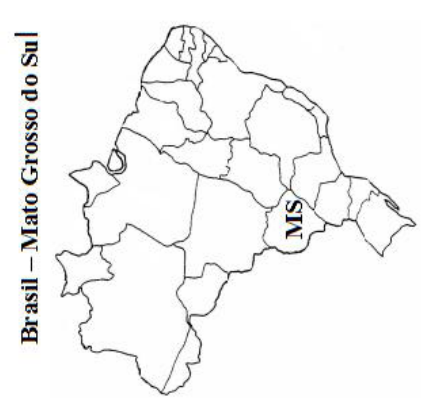

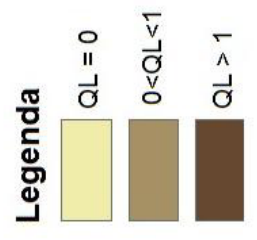

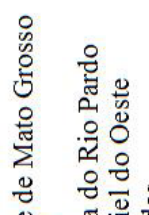

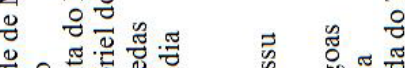

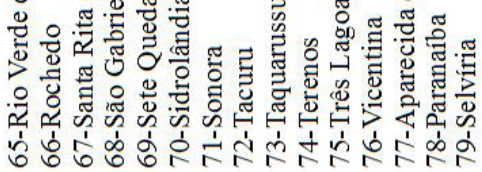
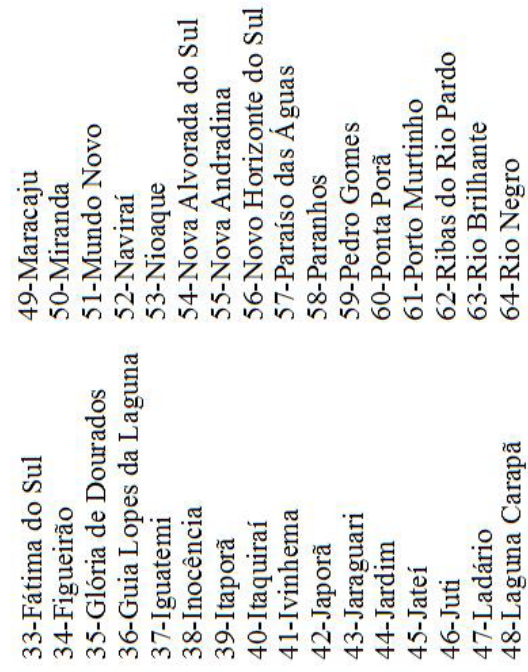

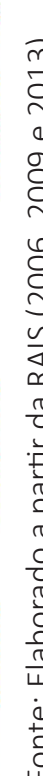


Ademais, as atividades turísticas resultam na atração de recursos econômicos para o local em que são desenvolvidas. Essa atração possibilita a ampliação de serviços públicos e ainda, a oferta de empregos na localidade. A atração do turista para uma determinada região extrapola o consumo de bens e serviços turísticos, pois o turista tende a consumir produtos produzidos nessa região, como por exemplo, matérias-primas alimentares que podem ter origem na agropecuária local (BARBOSA, 2005). Assim, o turismo tem efeitos diretos e indiretos no desenvolvimento dos municípios (BARRETO, 1995). Essas atividades são consideradas impulsos para o desenvolvimento a partir dos recursos que angariam para a região ou para o local. Contudo há necessidade de ações governamentais para que o turista venha a frequentar o local, a partir da garantia de estabilidade política e econômica. Além disso, os empresários precisam utilizar as potencialidades locais para oferecer produtos e serviços qualitativos; nesse quesito, o governo também pode auxiliar, oferecendo incentivos fiscais (ARAÚJO; LOPES; TINÔCO, 2012).

Em relação ao CRed (Tabela 1), observou-se que o valores para os municípios de Mato Grosso do Sul são próximos a zero. Dessa forma, entre os anos de 2006 e 2013, não houve mudanças significativas no padrão espacial de localização. Assim, Lacerda e Santos (2017) consideram que o emprego se manteve da mesma forma, ao longo do período analisado. Esse resultado pode ser um indicativo da necessidade de maiores investimentos em atividades turísticas em Mato Grosso Sul. Esses investimentos podem ser realizados a partir da ampliação das atividades oferecidas nos destinos turísticos tradicionais ou na identificação de novos destinos turísticos relacionados às potencialidades dos municípios.

Tabela 1 - CRed do emprego turístico de Mato Grosso do Sul - 2013 e 2006

\begin{tabular}{l|c}
\hline \multicolumn{1}{c|}{ Município } & CRed (2013-2006) \\
\hline Aparecida do Taboado & 0,00335 \\
Aquidauana & 0,02102 \\
Bataguassu & 0,00239 \\
Bodoquena & 0,00096 \\
Bonito & 0,01868 \\
Brasilândia & 0,00693 \\
Campo Grande & 0,05873 \\
Cassilândia & 0,00193 \\
Chapadão do Sul & 0,00070 \\
Corumbá & 0,04452 \\
Costa Rica & 0,00000 \\
Coxim & 0,00049 \\
Deodápolis & 0,00119 \\
Dourados & 0,00665 \\
Gloria de Dourados & 0,00096 \\
Ivinhema & 0,00217 \\
Jardim & 0,00096 \\
Jatei & 0,07416 \\
Ladário & 0,00916 \\
Maracaju & 0,00144 \\
Miranda & 0,00069 \\
Mundo Novo & 0,00049 \\
Naviraí & 0,00144 \\
Nova Alvorada do Sul & 0,00048 \\
Nova Andradina & 0,00048 \\
Paranaíba & 0,00145 \\
Mana & \\
\hline
\end{tabular}




\begin{tabular}{l|c}
\hline \multicolumn{1}{c|}{ Município } & CRed (2013-2006) \\
\hline Ponta Porã & 0,01930 \\
Porto Murtinho & 0,00245 \\
Ribas do Rio Pardo & 0,00048 \\
Rio Brilhante & 0,00410 \\
Rio Negro & 0,00000 \\
Rio Verde de Mato Grosso & 0,00145 \\
São Gabriel do Oeste & 0,00526 \\
Sete Quedas & 0,00048 \\
Sidrolândia & 0,01579 \\
Sonora & 0,00386 \\
Três Lagoas & 0,00332 \\
Vicentina & 0,00097 \\
\hline
\end{tabular}

Fonte: Elaborado a partir da RAIS (2006, 2009 e 2013).

Além disso, considera-se que, nas atividades turísticas, como em qualquer outra atividade econômica, o aumento da demanda pode refletir diretamente no aumento do emprego gerado na localidade em que a atividade é desenvolvida (NADJBERG; IKEDA, 1999). O aumento do emprego implica o aumento do consumo, tendo em vista que pessoas empregadas possuem recursos disponíveis, que podem ser destinados ao consumo de produtos e serviços como forma de satisfazer suas necessidades (PINTOR et al., 2016). Corrobora Lickorish (2000) ao considerar o efeito multiplicador econômico relacionado às atividades turísticas. Um bom destino turístico cria a necessidade de novos comércios no local, até mesmo a comercialização de produtos e serviços antes não disponíveis.

O CL está representado na Figura 2, por microrregião do estado. Esse indicador é utilizado para identificar padrões de concentração de determinada atividade por região. Depreende-se que os resultados, nas microrregiões e em ambos os anos, são próximos a zero. Dessa forma, indica-se que o emprego turístico nas microrregiões está distribuído da mesma forma que o de outras atividades da economia. Desse modo, não há padrão específico para os empregos gerados pelo turismo, assim não há concentração dessa atividade na região (DELGADO; GOLDINHO, 2002).

Figura 2 - CL do emprego turístico das microrregiões de Mato Grosso do Sul, anos 2006 e 2013

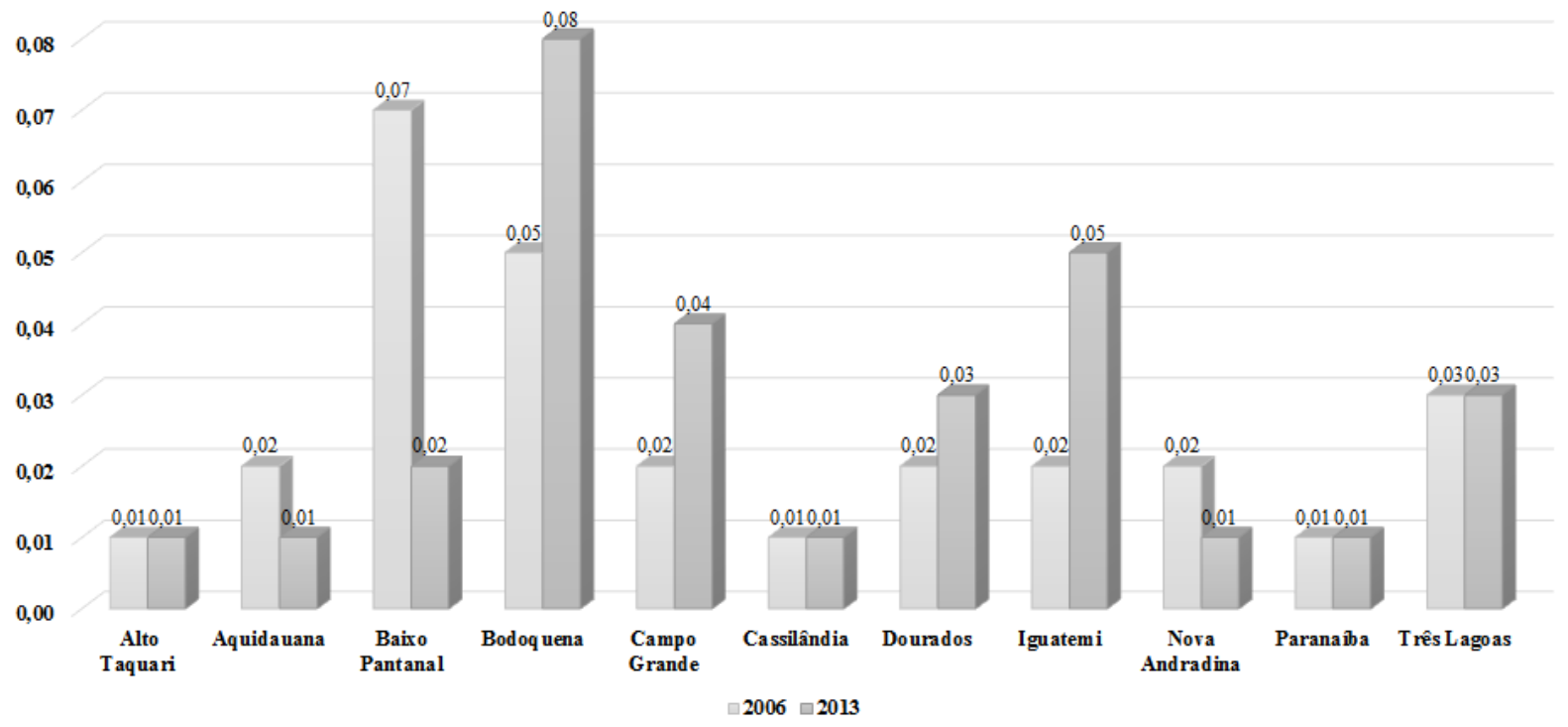

Fonte: Elaborado a partir da RAIS (2006, 2009 e 2013). 
O PR indica a participação percentual do emprego turístico de Mato Grosso do Sul, na oferta de empregos da mesma atividade do país (CROCCO et al., 2006). A Tabela 2 informa sobre o PR, para os anos de 2006, 2009 e 2013, em que se observa a participação dos empregos de Mato Grosso do Sul, a qual não foi constante no país, sendo 2009 o ano em que a participação do estado apresentou o maior percentual.

Tabela 2 - PR do emprego turístico de Mato Grosso do Sul, anos 2006, 2009, 2013

\begin{tabular}{cccc}
\hline PR & $\mathbf{2 0 0 6}$ & $\mathbf{2 0 0 9}$ & $\mathbf{2 0 1 3}$ \\
\hline Mato Grosso do Sul & 1,44 & 1,56 & 1,37 \\
\hline
\end{tabular}

Fonte: Elaborado a partir da RAIS (2006, 2009 e 2013).

Verifica-se que, nos municípios de Mato Grosso do Sul onde as atividades turísticas são desenvolvidas, como o município de Bonito, em que se iniciam as atividades na década de 1970, a população reconhece a importância dessa atividade econômica para a geração de emprego e renda (FAGUNDES; ASHTON, 2016). O mesmo ocorre na região do Pantanal, em que, além das atividades do agronegócio, há oferta de empregos relacionados ao ecoturismo (CASTELÃO et al., 2017). Além disso, acredita-se que as atividades turísticas devem aumentar a participação na geração de empregos no estado e que deverá haver um impulso no desenvolvimento das regiões de Mato Grosso do Sul (ROBERTO; LOURENÇO; ANTUNES, 2001).

\section{CONSIDERAÇÕES FINAIS}

O turismo é compreendido como uma atividade que pode ser utilizada como estratégia para o desenvolvimento local e regional. Os atrativos turísticos podem conquistar pessoas de outras regiões para consumir serviços e produtos oferecidos pelos moradores locais. A partir dessa consumação, novos empregos e renda são gerados. Além disso, a partir das atividades turísticas oferecidas, outros setores da economia são impactados pelos gastos que o turista realiza na localidade. Dessa forma, o local ou a região recebe recursos econômicos, oriundos de outras regiões.

O estado de Mato Grosso do Sul é uma região biodiversa, constituído por recursos naturais característicos de seus três biomas (Cerrado, Mata Atlântica e Pantanal). Os gestores, em alguma medida, têm investido na diversificação das atividades econômicas realizadas no estado, na qual uma de suas apostas é o turismo, principalmente atividades vinculadas ao turismo de natureza, ecoturismo entre outros que possam ser caracterizados pelo uso dos recursos naturais. Nessas atividades, há também a participação dos residentes locais, a partir da criação de Reservas Privadas do Patrimônio Natural, que tem a possibilidade de conservar os recursos naturais, a partir de seu uso sustentável.

Em ambos os casos, por iniciativa pública ou privada, percebe-se que as atividades turísticas possibilitam a geração de empregos. Pelo que foi observado nos dados da pesquisa, os municípios tradicionais, ou seja, aqueles que apresentam um histórico de atividades turísticas, mantêm sua característica no decorrer dos anos. São estes Aquidauana, Corumbá, Bonito, Ponta Porã e Porto Murtinho, os quais possibilitam atrair pessoas para a oferta de serviços turísticos na região em que estão inseridos. Para isso, há a necessidade de interação das lideranças locais e políticas, de forma a fomentar o desenvolvimento da região, por meio do turismo. 


\section{REFERÊNCIAS}

ANTHOPOULOU, T.; MELISSOURGOS, Y. Agri-tourism: in between rural change, tourism restructuring and environmental imperatives. In: HOLDEN, A.; FENNELL, D. A. (Ed.). The Rutledge handbook of tourism and the environment. Hoboken: Taylor and Francis, 2012.

ARAÚJO, L. L. B. A aplicação do conceito de região no Plano de Desenvolvimento Sustentável da Região Turística (PDSRT) do Meio-Norte (Brasil). Geografia Ensino \& Pesquisa, Santa Maria, v. 18, n. 2, p. 25-38, 2014.

ARAÚJO, R. M.; LOPES, A. O. B.; TINÔCO, D. S. Turismo como vetor de desenvolvimento local: um olhar através das ideias de Theodor Adorno e Max Horkheimer. Revista Turismo em Análise, São Paulo, v. 23, n. 1, p. 104-27, 2012.

BAPTISTA, L. T. D.; PEREIRA, C. H.; SONAGLIO, C. M. Dinâmica do setor turístico em Ponta Porã-MS, Brasil. Revista Iberoamericana de Turismo, Penedo, v. 6, n. 2, p. 118-37, 2016.

BARBOSA, F. F. O turismo como um fator de desenvolvimento local e ou regional. Caminhos de Geografia, Uberlândia, v. 10, n. 14, p. 107-14, 2005.

BARRETO, M. Manual de iniciação ao estudo do turismo. Campinas: Papirus, 1995.

BASTOS, S. Q. A.; ALMEIDA, B. B. M. M. Metodologia de identificação de aglomerações industriais: uma aplicação para Minas Gerais. Economia, Selecta, Brasília-DF, v. 9, n. 4, 63-86, dez. 2008.

BRASIL. Ministério da Economia. Relação Anual de Informações Sociais (RAIS). Brasília, DF, [s.d.].

CASTELÃO, R. A.; SOUZA, C. C.; FRAINER, D. M.; REIS NETO, J. F. "Empregos Verdes” na região do Pantanal brasileiro. Sustentabilidade em Debate, v. 8, n. 3, p. 126-37, 2017.

CROCCO, M. A.; GALINARI, R.; SANTOS, F.; SIMÕES, R. Metodologia de identificação de aglomerações produtivas locais. Nova Economia, Belo Horizonte, v. 16, n. 2, p. 211-41, 2006.

DELGADO, A.; GODINHO, I. Medidas de localização das actividades e de especialização regional. In: COSTA, J. (Coord.). Compêndio de economia regional. Lisboa: APDR, 2002. p. 723-42.

DORATIOTO, F. Maldita Guerra: nova história da Guerra do Paraguai. São Paulo: Companhia das Letras, 2002.

DURHAM, W. H. The challenge ahead. In: STRONZA, A.; DURHAM, W. H. (Ed.). Ecotourism and conservation in the Americas. CABI: Wallingford, 2008. p. 265-71.

EICHENBERG, F. O.; SILVA, C. A. Políticas públicas de turismo no Brasil: normalização em turismo de natureza e a experiência do programa aventura segura. Turydes- Revista de investigación en turismo y desarrollo local, Málaga, v. 6, n. 15, dez. 2013.

FAGUNDES, C.; ASHTON, M. S. G. A Oferta turística em Bonito, Mato Grosso do Sul, Brasil: o potencial criativo como diferencial competitivo. Revista Rosa dos Ventos - Turismo e Hospitalidade, Caxias do Sul, v. 8 , n. 1, p. 1-15, 2016.

GARMS, A. Pantanal: o mito e a realidade. In: SIMPÓSIO SOBRE RECURSOS NATURAIS E SOCIOECONÔMICOS DO PANTANAL, 4., 2004, Corumbá. Anais [...]. Corumbá: Embrapa Pantanal, 2004. p. 23-37.

GURGEL, Geraldo. Mato Grosso do Sul tem novo mapa turístico. Jul. 2016. Disponível em: http:// www.turismo.gov.br/\%C3\%BAltimas-not\%C3\%ADcias/6484-mato-grosso-do-sul-tem-novo-mapatur\%C3\%ADstico.html. Acesso em: 10 mar. 2018. 
HOEFLE, S. W. Multi-functionality, juxtaposition and conflict in the Central Amazon: Will tourism contribute to rural livelihoods and save the rainforest? Journal of Rural Studies, v. 44, p. 24-36, 2016.

LACERDA, T. N.; SANTOS, J. M. Análise da concentração do emprego da agropecuária do estado do Pernambuco: 2000-2014. Revista de Desenvolvimento Econômico, v. 36, p. 246-64, 2017.

LEONEL, W.; MERCANTE, M. A.; SABINO, J.; SILVA, M. H. S. S.; MARIANO, M. A. P. Relação entre turismo e dinâmica da paisagem em Bonito (MS) na perspectiva do modelo GTP (Geossistema-Território-Paisagem). Revista Brasileira de Ecoturismo, São Paulo, v. 10, n. 2, p. 411-32, 2017.

LICKORISH, L. Introdução ao Turismo. Rio de Janeiro: Campus, 2000.

LIMA, J. F.; ALVES, L. R.; PEREIRA, S. M.; DE SOUZA, E. C.; JONER, P. R.; CAMARGO, A.; RODRIGUES, E. J.; ANDRADE, P. E. P. O uso das terras no sul do Brasil: uma análise a partir de indicadores de localização. Revista de Economia e Sociologia Rural, v. 44, n. 4, p. 677-94, 2006.

MARIANI, M. A. P. Turismo e meio ambiente no paraíso das águas. Campo Grande: UCDB, 2003.

MARIANI, M. A P.; SORIO, A.; ARRUDA, D. O. Carne ovina, turismo e desenvolvimento local: potencialidades para o Mato Grosso do Sul. Interações, Campo Grande, MS, v. 12, n. 1, p. 31-9, 2011.

MATO GROSSO DO SUL (Estado). Secretaria de Estado de Meio Ambiente e Desenvolvimento Econômico (SEMADE). Diagnóstico Socioeconômico de Mato Grosso do Sul. Campo Grande, 2015. Disponível em: http://www.semagro.ms.gov.br/wp-content/uploads/sites/157/2017/06/Diagnostico_Socioeconomico_ de_MS_20151.pdf. Acesso em: fev. 2018.

MATTEI, T. F.; MATTEI, T. S. Métodos de análise regional: um estudo de localização e especialização para a região Sul do Brasil. Revista Paranaense de Desenvolvimento, Curitiba, v. 38, n. 133, p. 227-43, 2017.

NADJBERG, S.; ILKEDA, M. Modelo de geração de emprego: metodologia e resultados. Rio de Janeiro: BNDS, out. 1999. (Textos para Discussão, n. 72).

OLIVEIRA, C. F. Ecoturismo como prática para o desenvolvimento socioambiental. Revista Brasileira de Ecoturismo, São Paulo, v. 4, n. 2, p. 184-95, 2011.

PEREIRA, C. H.; MARTINS, P. C. S.; LUNAS, J. R. S.; AQUINO, J. M. Efeito multiplicador do turismo na fronteira entre Brasil e Paraguai. Turismo \& Sociedade, Curitiba, v. 7, n. 4, p. 792-814, 2014. ISSN: 1983-5442

PINTOR, E.; KODAMA, A. K.; AGUILAR, C. J. P.; PIFFER, M. A dinâmica econômica do município de Foz do Iguaçu de 2002 até 2012. Revista Orbis Latina, Foz do Iguaçu, v. 6, n. 1, p. 71-88, 2016.

PONTA PORÃ (Cidade). Secretaria de Indústria Comércio e Turismo Perfil Socioeconômico Fronteira Pedro Juan- Ponta Porã. Ponta Porã: Prefeitura Municipal, 2013.

ROBERTO, C.; LOURENÇO, F.; ANTUNES, P. A Ferrovia e o turismo no Mato Grosso do Sul. Multitemas, Campo Grande, MS, n. 20, p. 47-49, 2001.

SANTOS, D. R. L.; SILVA, W. G.; MOREIRA JUNIOR, O. Ponta Porã: um micropolo geográfico de ligação na fronteira brasileira. GeoFronter, Campo Grande, MS, v. 1, n. 1, p. 126-50, 2015.

SCÓTOLO, D.; PANOSSO NETTO, A. Contribuições do turismo para o desenvolvimento local. Revista de Cultura e Turismo, Ilhéus, v. 1, p. 36-59, 2015. 
STRONZA, A. The bold agenda of ecotourism. In: STRONZA, A.; DURHAM, W. H. (Ed.). Ecotourism and conservation in the Americas. Wallingford: CABI, p. 3-17, 2008.

VIDIGAL, V. G.; CAMPOS, A. C.; ROCHA, C. B. Especialização produtiva nos Arranjos Produtivos Locais (APL) de calçados do Brasil, 1995-2006. Estudos do CEPE, Santa Cruz do Sul, RS, n. 30, p. 30-53, 2009.

VIOLIN, F. L.; ALVES, G. L. Da pesca ao natural: trajetória do turismo em Mato Grosso do Sul (1970 a 2015). Sustentabilidade em Debate, Brasília, v. 8, n. 2, p. 130-46, 2017.

WEARING, S.; NEIL, J. Ecoturismo: impactos, potencialidades e possibilidades. 2. Ed. Sydney: Manole, 2014.

WORLD TOURISM ORGANIZATION (UNWTO). Tourism towards 2030: global overview. Madrid: UNWTO, 2011.

\section{Sobre os autores:}

Luciana Virginia Mario Bernardo - Doutoranda em Desenvolvimento Regional e Agronegócio pela Universidade Estadual do Oeste do Paraná (Unioeste). Mestre em Agronegócios e Bacharel em Ciências Contábeis pela Universidade Federal da Grande Dourados (UFGD). E-mail: lucianamario@yahoo.com.br, Orcid: http://orcid.org/0000-0001-7615-0433

Maycon Jorge Ulisses Saraiva Farinha - Doutorando em Geografia, mestre em Agronegócios, Licenciado e Bacharel em Geografia pela Universidade Federal da Grande Dourados (UFGD), e licenciado em Pedagogia pelo Centro Universitário da Grande Dourados (UNIGRAN). E-mail: maycondds@hotmail.com, Orcid: http://orcid.org/0000-0001-9405-2511 